\title{
A New Feature of Nesting Ecology in the Vulnerable European Turtle Dove: Nest Site and Nesting Tree Sharing with Coexisting Species at Three North African Wetlands
}

\author{
Wafae Squalli $\left(\mathbb{D},{ }^{1}\right.$ Ismail Mansouri $\left(\mathbb{D}^{1},{ }^{1}\right.$ Driss Ousaaid $\left(\mathbb{D}^{2},{ }^{2}\right.$ Badr Ben Hichou, ${ }^{3}$ \\ Hamid Achiban, ${ }^{4}$ Fatima Fadil, ${ }^{1}$ and Mohamed Dakki ${ }^{3}$ \\ ${ }^{1}$ Laboratory of Functional Ecology and Genie of Environment, Faculty of Sciences and Technology, USMBA, Fez, Morocco \\ ${ }^{2}$ Laboratory of Natural Substances, Pharmacology Environment, Modeling, Health and Quality of Life, \\ Faculty of Sciences Dhar El Mahraz, University Sidi Mohamed Ben Abdellah, Fez, Morocco \\ ${ }^{3}$ Laboratory of Géo-Biodiversity and Naturel Patrimony, Scientific Institute (Mohammed V University), Av. Ibn Battota, \\ 10 BP 703, Rabat, Morocco \\ ${ }^{4}$ Laboratory of Geo-Environmental, Analysis Planning-Sustainable Development, Faculty of Sciences Dhar El Mahraz, \\ Sidi Mohamed Ben Abdelah University, Fez, Morocco
}

Correspondence should be addressed to Ismail Mansouri; mankhori@gmail.com

Received 26 March 2021; Accepted 4 January 2022; Published 24 January 2022

Academic Editor: Nathaniel Newlands

Copyright ( 92022 Wafae Squalli et al. This is an open access article distributed under the Creative Commons Attribution License, which permits unrestricted use, distribution, and reproduction in any medium, provided the original work is properly cited.

Investigations of niche splitting in the European turtle dove (Streptopelia turtur) have primarily addressed feeding habitats and foraging features and been limited to conspecific species, counting laughing dove and wood pigeon. The recent degradation of natural and suitable habitats for turtle doves, particularly in North Africa, would push this species to refuge in wetlands with a variety of other bird species. The understanding of potential cohabitation between doves and other species in these less disturbed ecosystems would help in the conservation measures of this declining game. This study, conducted from early March to September between 2015 and 2017, attempted to determine which species cohabit with turtle doves in three Northwest African wetlands in Morocco and how these species select nesting sites and trees. We used detrended corresponding analysis (DCA) to test the relevance of nest site and nesting tree variables in the nest distribution of the breeding species. The obtained results show a wide sharing of nest-niche between turtle doves and 7 breeding species, especially at the intermediate zone and downstream of the rivers. The lack of competition for food resources with neighbouring species may help in this harmonious sharing of both nesting sites and nesting trees. We further suggest guidelines for future research that seek to understand the spatiotemporal dynamics of species coexisting with turtle dove in the same habitats.

\section{Introduction}

The cohabitation of similar and different species that share resources in the same environment is of crucial interest in ecology $[1,2]$. To coexist, species should differ on at least one aspect of their ecological function and/or behavioural aspects $[3,4]$ and should use space and/or time differently at their environment. For illustration, species could use different food resources or their activity patterns could be separated in time [5]. Because the coexistence of similar species and the use of the same resources at the same time risk to create a hostile environment and/or antagonism behaviours [6,7], the difference is critical.

For bird species, particularly long distance migrants, nest site selection is of vital importance. These birds travel for a long distance from wintering to breeding grounds and any failure in nesting habitats would disturb whole life cycles. Consequently, the selection of nest location is considered the main adaptive response to a combination of climatic conditions $[8,9]$, nest predation pressure [10-12], and human disturbances $[13,14]$. Its selection is therefore vital for individual fitness. 
The present study analyses the patterns of nesting habitat selection of turtle doves in tree North African river wetlands to examine how they use nesting sites and nest support with different species that nest in the same habitats. In other words, we studied nest locations of all species that nest commonly with $S$. turtur in macrohabitat represented by river zones, including upstream, intermediate zone, and downstream, and in microhabitat reflected by nesting trees. The choice of river wetlands has two reasons. First, these natural habitats are less influenced by human activities in Northwest Africa [15, 16], and the monitoring of any ecological aspect will be less influenced by human pressure. Second, with the acceleration of desertification and climate change in North Africa $[17,18]$, wetlands, especially rivers, will be the latest and suitable refuge for resident and migratory species, including turtle doves for breeding and foraging [19], and thus, their analyses will open our eyes to appreciate their role in conservation measures of this declining game. The study of turtle doves' cohabitation with existing species in wetlands will evaluate their interactions as a community concerning habitat use and its implication for conservation purposes.

\section{Materials and Methods}

2.1. Study Area. Observations were made in Moulouya high plain, situated at the foot of Jbel Ayachi Mountain and the junction with the Middle Atlas chain. The high plain is located at an altitude of 1400-1600 m above sea level and is characterized by an arid climate, with cold winters [20]. The area is dominated by farmlands (804.354ha), forests (185.004 ha), and uncultivated lands (280.000 ha). Three study wetlands were selected and monitored from 2015 to 2017 (Figure 1). First, the Ansegmir River departs from the junction of the Middle Atlas Mountain chain and the Central high Atlas Mountain (classified as a site of biological and ecological interest) and finishes by the Hassan II dam in the north of Midelt city. Second, the Eastern Tablkhirt River departs from the northwest of Boumia city, crosses Zaida city, and finishes by the Hassan II dam. Third, the western part of the Tablkhirt River takes source from Imzil rural villages in the west and finishes north of Boumia city in the east. Along these rivers, we have noted a variety of plant species, including riparian vegetation and farm plants (Table 1), and these were distributed on each side of the river streams.

2.2. Sampling Design. Given that wetlands in Morocco, particularly rivers, are the only habitats in which avifauna and other species can live and act with minimum human disturbances [21] and are one of the favorable habitats for turtle doves during breeding and migration periods [22, 23], and fieldwork was exclusively carried out in these habitats.

The study took place during the breeding season, from early March to September, between 2015 and 2017. These periods were chosen based on the breeding periods of turtle doves in the North African zone, particularly in Moulouya high plain $[14,20,24]$. The study rivers (Figure 1) were initially divided into three zones: upstream in the top of the river, from mountain sources to the first farmlands in the plain; intermediate, which starts from the first farmlands under mountain foot to the finish line of irrigated perimeters; and downstream, located in the borders of irrigated lands to the nearest dam built on the monitored river. Each zone was assigned an exclusive numerical identifier. In each year, we systematically searched nests along the rivers with a method consisting of side by side (right and left sides of river stream) walked transects of $6-10 \mathrm{~km}$ per day, from 06.00 to 18.00 hours. To describe nest-niche of turtle doves, in every single transect (two transects simultaneously at both sides of the river), detected nests were assigned with a unique serial number (for good monitoring), identified (nesting species), localized (with phone GeoTracker software and then reported in an Open Source GIS (Quantum GIS v1.7.3), and characterized (two categories: nesting tree and breeding zone). In parallel, nest dimensions (three categories: large axis (large diameter or length), small axis (small diameter or width), and depth (thickness or cup depth)), nest placement (two categories: nest height upon the ground $(\mathrm{NH})$ and nesting tree height $(\mathrm{NTH})$ ), and distance between neighbouring nests (intra and interspecific) were measured with a clinometer, and long distances were extracted from Google Earth (Quantum GIS). Nests were monitored three to two times per week in each river, from nesting to loss of clutch or survival of chicks.

2.3. Statistical Analyses. We tested for normality and homogeneity of variance for all parameters (variables) via the Kolmogorov-Smirnov test. The dimensions of turtle dove' nests were measured, and results were given as sample size and mean \pm SD. We also checked for possible correlations among variables of the dove nests by using Pearson's rank correlation $(r)$ index. To evaluate differences in distances (cm) separating nests of cohabiting species on the same nesting trees and on the same tree species, we used one-way ANOVA.

To assess the main factors characterizing nest-niche of doves and cohabiting species (blackbird, European serin, Western Bonelli's Warbler, and woodchat shrike), the depth of nest' cup (Depth), the height of nest supporting tree (H. support), the large axis of the nest (length), the height of the nest above the ground (N. height), and small axis of the nest (width) were considered as illustrative factors (principal factors), while nests of birds were counted as response variables and were examined with PCA, where only factors with eigenvalues $>1.0$ were considered. We interpreted the ecological meaning of the principal components, which explicates the highest amount of combined variation within the nest characteristic data, by analyzing the component loadings of every variable [25].

To define nesting sites and cohabitation between doves and cohabiting species, the breeding sites (three zones: upstream, intermediate zone, and downstream) and nesting trees (plum, Tamarix, reed, poplar, wild rose, Salix, hawthorn, blackberry, white willow, and quince) were considered as independent variables, while nests $(n=453)$ of 


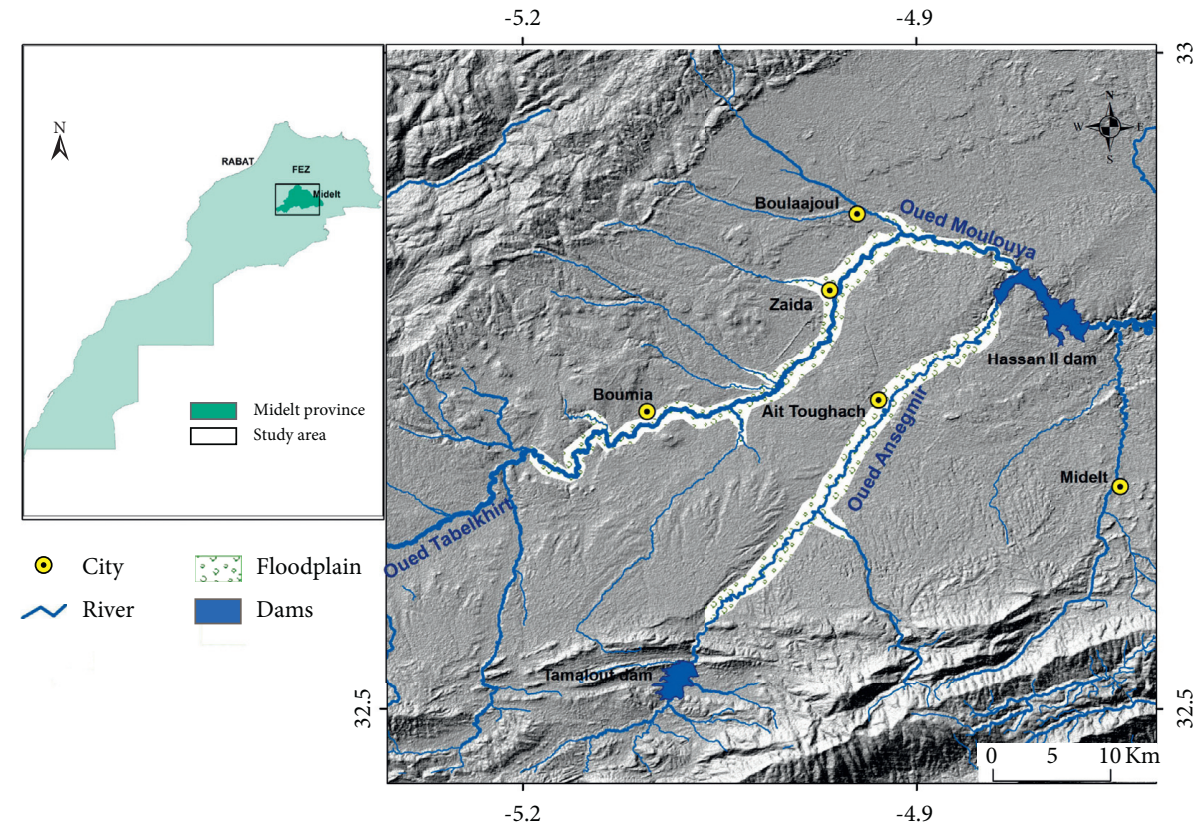

Figure 1: Study rivers of Ansegmir, Moulouya, and Tablkhirt in Moulouya watershed at Midelt Province, Morocco.

TABle 1: Abundance of principal vegetation genus identified in the studied rivers at Midelt, Morocco.

\begin{tabular}{|c|c|c|c|c|}
\hline Type & Plants genius & Ansegmir & Eastern Tablkhirt & Western Tablkhirt \\
\hline \multirow{10}{*}{ Wild riparian genus } & Poplar sp. & +++++ & +++++ & +++ \\
\hline & Salix sp. & +++++ & ++++ & +++++ \\
\hline & Rosa sp. & +++ & ++++++ & +++ \\
\hline & Phragmites sp. & +++ & +++++ & +++ \\
\hline & Typha sp. & ++ & ++ & ---- \\
\hline & Crataegus sp. & ++ & ++ & ++++ \\
\hline & Rubus sp. & +++ & ++ & + \\
\hline & Juncus sp. & ++ & ++ & ++ \\
\hline & Tamarix sp. & ++ & ++ & - \\
\hline & Pinus sp. & + & + & + \\
\hline \multirow{4}{*}{ Cultivated genus } & Malus sp. & +++++ & +++++ & +++++ \\
\hline & Prunus sp. & +++ & +++ & +++ \\
\hline & Cydonia sp. & +++ & +++ & +++ \\
\hline & Pyrus sp. & ++ & ++ & + \\
\hline $\begin{array}{l}+++++ \\
\text { Very abundant }\end{array}$ & $\begin{array}{c}+++ \\
\text { Abundant }\end{array}$ & $\begin{array}{c}++ \\
\text { Less abundant }\end{array}$ & $\begin{array}{c}+ \\
\text { Rare }\end{array}$ & $\begin{array}{c}- \\
\text { Absent }\end{array}$ \\
\hline
\end{tabular}

breeding species $(n=8)$ (birds: Ciconia ciconia, Lanius senator, Phylloscopus bonelli, Luscinia megarhynchos, Passer domesticus, Serinus serinus, Streptopelia turtur, and Turdus merula) were considered as dependent variables (response: 1 nesting or 0 absence of nest), and eigenvalues were $>1.0$ ). Finally, statistic tests were computed in the STATGRAPHICS Centurion software, version XVII. Results were considered significant at $p<0.05$.

\section{Results}

3.1. Habitat and Nest Tree Sharing. In studied wetlands, turtle dove shared breeding sites with a variety of bird species. Seven species, including Western Bonelli's Warbler (Phylloscopus bonelli), common blackbird (Turdus merula), European serin (Serinus serinus), white stork (Ciconia ciconia), common nightingale (Luscinia megarhynchos), woodchat shrike (Lanius senator), and house sparrow (Passer domesticus) were found in the same nesting sites with turtle doves (Figure 2). However, the distribution of these species differed between river zones and nesting supports. At upstream, four species, counting Bonelli's Warbler, blackbird, European serin, woodchat shrike were inventoried as breeders on plum sp., Tamarix sp., and reed sp. trees, while turtle dove was absent at this zone. At the intermediate zone, 8 birds were listed as breeders on different supports. The group counting turtle dove, blackbird, and woodchat shrike preferred wild rose, blackberry, and hawthorn for nesting, while the group with Bonelli's Warbler, common nightingale, European serin, and house sparrow preferred Salix sp. as nesting trees. The white stork built its nest alone on Poplar sp. At downstream, only four species were inventoried as 


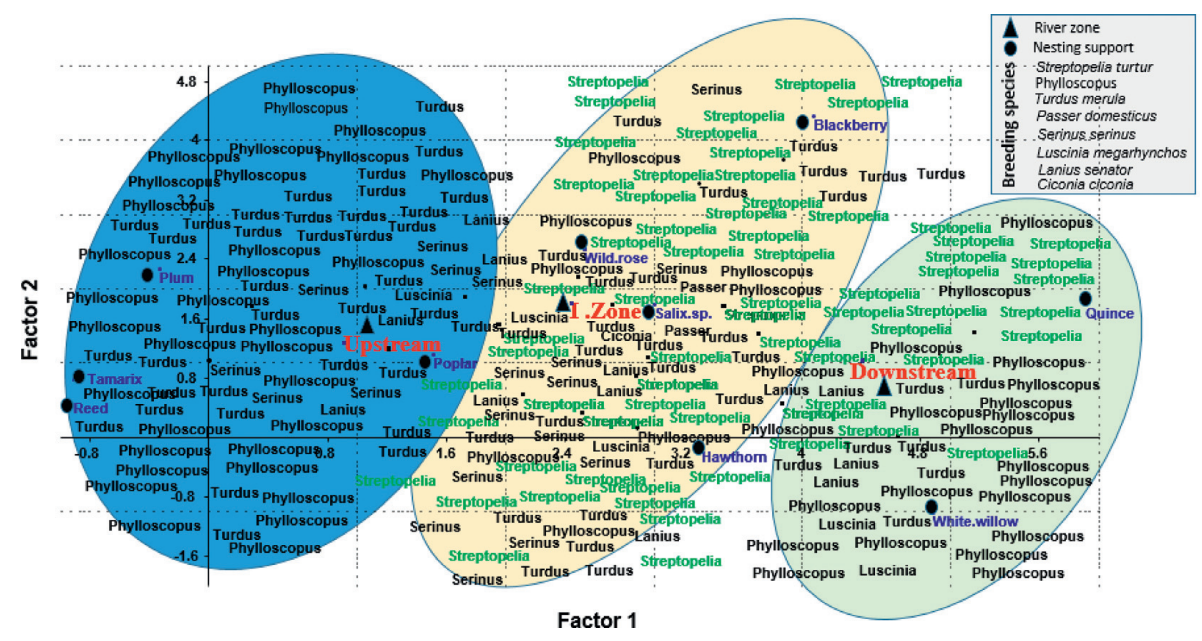

Figure 2: Distribution of nesting species (birds: Ciconia ciconia, Lanius senator, Phylloscopus bonelli, Luscinia megarhynchos, Passer domesticus, Serinus serinus, Streptopelia turtur, and Turdus merula), used trees (nesting trees: plum, Tamarix, reed, poplar, wild rose, Salix, hawthorn, blackberry, white willow, and quince), and river' zones (breeding habitats (rivers divided into three zones): upstream, intermediate zone, and downstream) during breeding seasons between 2015 and 2017.

breeders with turtle doves. Though, doves shared quince sp. as nesting support only with Bonelli's Warbler, while blackbird, common nightingale, and woodchat shrike shared white willow as a nesting tree.

3.2. Nest Placement and Dimension. In terms of nest placement, turtle doves built their nests $(n=20)$ on an average height of $3.74 \pm 1.83 \mathrm{~m}$ above the ground. In terms of dimensions, nests of doves were categorized by a large axis of $14.105 \pm 0.41 \mathrm{~cm}$, a small axis of $11.43 \pm 0.28 \mathrm{~cm}$, and a depth of $4.79 \pm 0.26 \mathrm{~cm}$ on average. Furthermore, only small axis was correlated with the large axis (Spearman rank correlations; $n=20, r=0.51, p=0.0253$ ) and depth (Spearman rank correlations; $n=20, r=0.73, p=0.01$ ).

In comparison with neighbouring species (that share the same nesting trees) (Figure 3), doves' nests were characterized by greater dimensions, mainly length (large axis) and width (small axis) of the nests (G1, Figure 3). On the other side, blackbird and Western Bonelli's Warbler built nests characterized by higher depth (cup depth) to protect their clutches (G2, Figure 3). While, the European serin (G3, Figure 3) builds nests characterized by superior height for both nesting supports and nest height upon the ground.

\section{Discussion}

From 1960 to 2020, the majority of studies concerning turtle doves investigated this game separately from other species that could exist in the same habitats, and this will miss a piece of precious information that would help in the conservation of this declining migrant bird [26]. In the best case, turtle doves were studied comparatively with conspecific competitors (Columbidae), such as laughing dove, collared dove, stock dove, and wood pigeon, mainly in geographical distribution [27-32], in feeding competition [29, 33], in breeding biology $[26,34-36]$, and in parasite infestation $[37,38]$. On the contrary, this study has situated turtle doves among interspecific breeding species in wild nesting sites.

As expected, this study showed clear evidence of interspecific interactions between the globally threatened turtle dove and other cohabiting bird species during breeding periods. Obtained results unveil sharing of breeding habitats and nesting sites in studied wetlands. Turtle doves nested in river wetlands with 7 other species, including resident birds, such as the blackbird, house sparrow, European serin, and Western Bonelli's Warbler, and migratory birds, such as white stork, common nightingale, and woodchat shrike. This highlights for the first time an interspecific cohabitation behaviour in turtle doves, which was neglected in previous studies [31,39]. In terms of macrohabitat (river' zones), turtle doves nested in downstream and intermediate zones at three different rivers, regularly with 7 species from 2015 to 2017 . In terms of microhabitat (nesting trees), at intermediate zone, doves nested commonly with blackbird on wild rose and blackberry trees and with Western Bonelli's Warbler, blackbird, and the common nightingale on hawthorn trees. At downstream, turtle doves nested separately on quince trees, while Western Bonelli's Warbler, blackbird, and common nightingale nested on white willow trees.

This kind of interactions has been documented, particularly between some dove species during the breeding season, for instance, between the turtle dove and the collared dove in Spain and Morocco $[28,32,36,40]$ and between the white-winged dove Zenaida asiatica and the mourning dove in the USA [41], and between doves and pigeons, for instance, between turtle doves and wood pigeon [39]. In North African ecosystems, migratory turtle doves and resident, collared dove, wood pigeons, and laughing dove segregated nesting tree supports and breeding sites in order to reduce potential competition for food resources and nesting supports [32,36,39], which is in contradiction with our results. In this study, turtle doves shared the same habitats and same nesting trees with at least three species, including migratory 


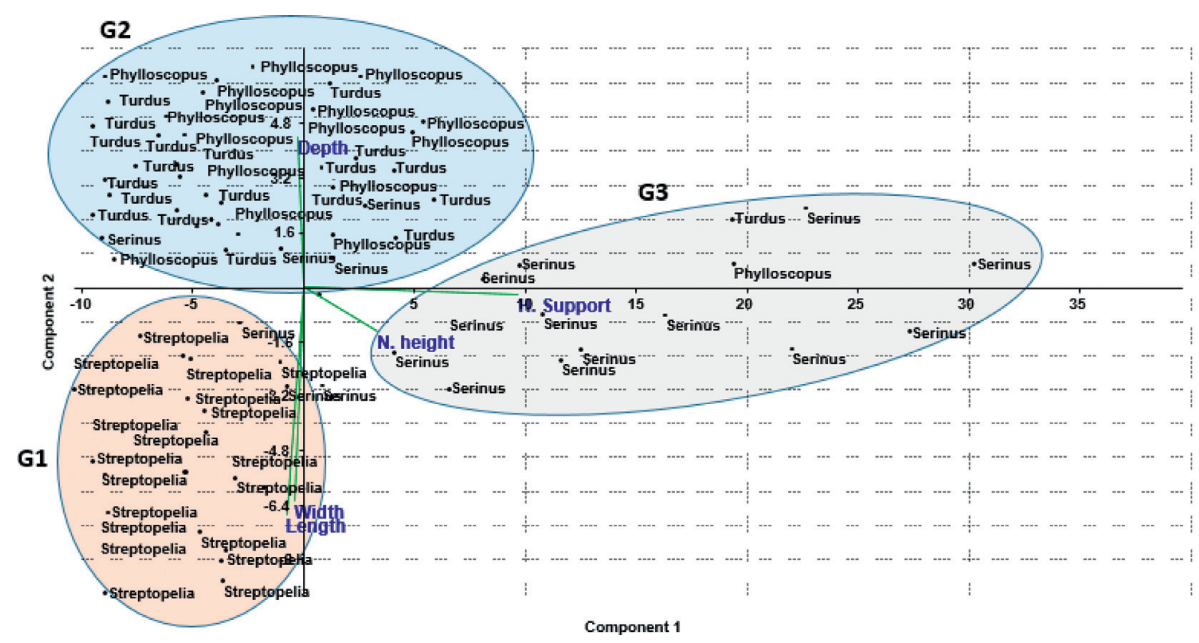

Figure 3: Principal features (depth, depth of nest cup; H. support, height of nest supporting tree; length, large axis of the nest; N. height, height of the nest above the ground; width, small axis of the nest) characterizing turtle doves (Streptopelia turtur) and neighbouring species nests (Phylloscopus bonelli, Luscinia megarhynchos, Serinus serinus, and Turdus merula) in the studied rivers at Moulouya, Morocco.

TABle 2: Comparison of distances separating dove nests and nests of neighbouring species using the same nesting trees (turtle dove and blackbird, Bonelli's Warbler, and woodchat shrike), tested using the one-way ANOVA test.

\begin{tabular}{|c|c|c|c|c|c|}
\hline \multirow{2}{*}{ Parameters } & \multicolumn{3}{|c|}{ Cohabiting species } & \multicolumn{2}{|c|}{ Statistic test } \\
\hline & S. turtur-T. merula & S. turtur-P. bonelli & S. turtur-L. senator & $F$ & $P$ \\
\hline Number of nests on the same tree support & 7 & 9 & 2 & - & - \\
\hline Number of nests on the same three species & 19 & 25 & 6 & - & - \\
\hline Distances between nests on the same tree support & $22.88 \pm 4.77 \mathrm{~cm}$ & $22.88 \pm 4.77 \mathrm{~cm}$ & $172.5 \pm 115.39 \mathrm{~cm}$ & 11.413 & 0.000 \\
\hline Distances between nests on the same species of tree & $31.22 \pm 5.61 \mathrm{~m}$ & $37.33 \pm 7.47 \mathrm{~m}$ & $67.87 \pm 32.00 \mathrm{~m}$ & 1.041 & 0.369 \\
\hline
\end{tabular}

and resident birds ( 7 dove nests with 7 blackbird nests, 9 nests with Bonelli's Warbler, and 2 nests with woodchat shrike on the same nesting trees). Moreover, in many cases, distances between dove nests and neighbouring species nests on the same trees were very close in the same breeding periods of all these species (between dove and Bonelli's Warbler on wild rose trees, nests were separated by $22.88 \pm 4.77 \mathrm{~cm}$ only, and between dove and blackbird on blackberry trees, $d=38 \pm 6.37 \mathrm{~cm}$ ) (Table 2).

The reason behind sharing (present study) or segregation (previous studies) [32, 36] of breeding habitats between migratory turtle doves and coexisting birds is suggested to be intraspecific competition. In fact, migratory turtle doves, resident laughing doves, and wood pigeons are strictly granivorous $[14,33,42-46]$ and are severe conspecific competitors at both wild and agricultural ecosystems $[39,45,47,48]$, and therefore, the segregation of breeding habitats and nesting trees will allow them to avoid any concurrence for breeding sites and feeding resources. The sharing of breeding sites and nesting trees by doves and interspecific birds such as blackbird and Bonelli's Warbler known for their insectivorous diet $[47,48]$ would not affect either breeding or feeding sources available for both sides of these guilds. Furthermore, turtle doves are currently documented to diversify feeding habitats far from nesting sites [14, 24], and thus, the sharing of nesting sites would not influence the availability of feeding resources close to or far from nesting habitats.
Concerning nest dimensions, among studied species, turtle doves were characterized by the largest nests (length and width), followed by blackbird with deep nests, while European serin and Bonelli's Warbler nests were the smallest. In addition, European serin nests were built on the highest height above the ground and nesting trees. These findings suggest that turtle dove and blackbird known for medium body size $[49,50]$ are building medium-sized nests, while European serin and Bonelli's Warbler built small nests in correlation to their body sizes [51]. Such results were demonstrated largely in bird communities [49, 52] and support that each species build a safe and comfortable nest in correlation to species body size in kind of species-specific nests and in order to ensure better clutch protection.

\section{Conclusion}

In summary, these data reinforce the lack of information on nest-niche selection of the globally threatened European turtle dove in the Mediterranean zone. This work shows that for breeding, turtle doves share nesting habitats and trees with different species, including migratory and resident birds. Furthermore, more detailed investigations are needed to allow deeper insights into the coexistence of turtle doves with concurrent and predatory species. Our future challenge is to understand the spatial and temporal dynamics of doves in harmony with the competitor and sociable species and to determine how these may cause a trend in the size of populations. 


\section{Data Availability}

All data used to support the results of the study have been included in the manuscript.

\section{Conflicts of Interest}

The authors declare they have no conflicts of interest.

\section{Authors' Contributions}

IS and WS designed the study. IM, WS, HA, DO, BBH, MD, and FF collected the life history data in fieldwork. IM and WS analyzed the data and wrote the manuscript. All authors read and approved the final manuscript.

\section{Acknowledgments}

The authors are grateful to their colleagues who helped in collecting data.

\section{References}

[1] F. Coppola, C. Dari, G. Vecchio, D. Scarselli, and A. Felicioli, "Cohabitation of settlements among crested porcupine (Hystrix cristata), red fox (Vulpes vulpes) and European badger (Meles meles)," Current Science, vol. 119, no. 5, p. 817, 2020.

[2] T. T. Fernandes, W. Dáttilo, R. R. Silva, P. Luna, A. B. Braz, and M. S. C. Morini, "Cohabitation and niche overlap in the occupation of twigs by arthropods in the leaf litter of Brazilian Atlantic Forest," Insectes Sociaux, vol. 67, no. 2, pp. 239-247, 2020.

[3] N. C. Caceres, A. Machado, Spatial, dietary and temporal niche dimensions in ecological segregation of two sympatric, congeneric marsupial species," The Open Ecology Journal, vol. 6, no. 1, pp. 10-23, 2013.

[4] A. Golawski and Z. Kasprzykowski, "Comparative foraging behaviour of three species of shrike in southern Africa," African Zoology, vol. 53, no. 2, pp. 69-74, 2018.

[5] M. Tokeshi, Species Coexistence: Ecological and Evolutionary Perspectives, Blackwell Science, Hboken, NJ, USA, 1999.

[6] M. C. Rodríguez-Rodríguez, P. Jordano, and A. Valido, "Functional consequences of plant-animal interactions along the mutualism-antagonism gradient," Ecology, vol. 98, no. 5, pp. 1266-1276, 2017.

[7] B. R. Hogan, M. M. Grigione, M. A. Marconi, R. E. Thomas, and R. J. Sarno, "Asymmetric antagonism between piping plovers (Charadrius melodus) and American oystercatchers (Haematopus palliatus), New York, USA," Waterbirds, vol. 41, no. 4, pp. 443-448, 2018.

[8] J. Ralston, W. V. DeLuca, R. E. Feldman, and D. I. King, "Realized climate niche breadth varies with population trend and distribution in North American birds," Global Ecology and Biogeography, vol. 25, no. 10, pp. 1173-1180, 2016.

[9] J. W. H. Ferguson and W. R. Siegfried, "Environmental factors influencing nest-site preference in white-browed sparrowweavers (Plocepasser mahali)," The Condor: Ornithological Applications, vol. 91, no. 1, pp. 100-107, 1989.

[10] M. Yanes, J. Herranz, and F. Suárez, "Nest microhabitat selection in larks from a European semi-arid shrub-steppe: the role of sunlight and predation," Journal of Arid Environments, vol. 32, no. 4, pp. 469-478, 1996.
[11] R. Barrientos, F. Valera, A. Barbosa, C. M. Carrillo, and E. Moreno, "Plasticity of nest-site selection in the trumpeter finch: a comparison between two different habitats," Acta Oecologica, vol. 35, no. 4, pp. 499-506, 2009.

[12] J. H. Devries, R. G. Clark, and L. M. Armstrong, "Dynamics of habitat selection in birds: adaptive response to nest predation depends on multiple factors," Oecologia, vol. 187, no. 1, pp. 305-318, 2018.

[13] S. Rao and V. K. Koli, "Edge effect of busy high traffic roads on the nest site selection of birds inside the city area: guild response," Transportation Research Part D: Transport and Environment, vol. 51, pp. 94-101, 2017.

[14] I. Mansouri, M. K. Al-Sadoon, M. Rochdi, B. A. Paray, M. Dakki, and L. Elghadraoui, "Diversity of feeding habitats and diet composition in the turtle doves Streptopelia turtur to buffer loss and modification of natural habitats during breeding season," Saudi Journal of Biological Sciences, vol. 26, no. 5, pp. 957-962, 2019.

[15] A. Roccati, F. Faccini, F. Luino, J. V. De Graff, and L. Turconi, "Morphological changes and human impact in the Entella River floodplain (Northern Italy) from the 17th century," Catena, vol. 182, Article ID 104122, 2019.

[16] E. Massoud, T. Massoud, B. Guan et al., "Atmospheric rivers and precipitation in the middle east and north africa (Mena)," Water, vol. 12, no. 10, p. 2863, 2020.

[17] M. Hulme and M. Kelly, "Exploring the links between desertification and climate change," Environment: Science and Policy for Sustainable Development, vol. 35, no. 6, pp. 4-45, 1993.

[18] J. Huang, J. Zhang, Y. Zhang, X. Guan, and R. Guo, Global Desertification Vulnerability to Climate Change and Human Activities-Huang-2020_Land Degradation \& Development, Wiley Online Library, Hoboken, NJ, USA, 2020.

[19] G. Chiatante, Z. Porro, and M. Alberto, "The importance of riparian forests and tree plantations for the occurrence of the European Turtle Dove Streptopelia turtur in an intensively cultivated agroecosystem," Bird Conservation International, 2020.

[20] I. Mansouri, D. Ousaaid, W. Squalli, H. Sqalli, L. El Ghadraoui, and M. Dakki, "The turtle dove (Streptopelia turtur) in Midelt plain, Morocco: nesting preferences and breeding success versus the impact of predation and agricultural practices," Journal of Animal Behaviour and Biometeorology, vol. 8, pp. 206-214, 2020.

[21] M. Dakki, B. El FEllah, and A. Qninba, Rivers' Natural Reservoirs: New Inputs to the Classification of Mediterranean and Saharan Wetlands, Bulletin de l'Institut Scientifique, Rabat, Morocco, 2020.

[22] M. A. Salim and S. A. Abed, "Avifauna diversity of bahr Alnajaf wetlands and the surrounding areas, Iraq," Jordan Journal of Biological Sciences, vol. 10, no. 3, 2017.

[23] A. S. Ringim and S. I. Muhammad, "A checklist for birds of Hadejia-Nguru Wetlands, Nigeria," Dutse Journal of Pure and Applied Science, vol. 3, pp. 15-28, 2017.

[24] A. EL Hassani, M. Dakki, and L. El Ghadraoui, "Chronologie de la reproduction de la Tourterelle des bois Streptopelia turtur arenicola dans la région de Taroudant (Maroc)," Bulletin de l'Institut Scientifique, Rabat, Section Sciences de la Vie, vol. 40, pp. 11-22, 2018.

[25] K. McGarigal, S. Cushman, and S. Stafford, Multivariate Statistics for Wildlife \& Ecology Research, Springer, Berlin, Germany, 2000. 
[26] S. Hanane, "The European turtle-dove Streptopelia turtur in Northwest africa: a review of current knowledge and priorities for future research," Arla, vol. 64, no. 2, pp. 273-287, 2017.

[27] C. M. Romagosa and R. F. Labisky, "Establishment and dispersal of the eurasian collared-dove in Florida," Journal of Field Ornithology, vol. 71, no. 1, pp. 159-166, 2000.

[28] G. Rocha-Camarero and S. H. de Trucios, "The spread of the Collared Dove Streptopelia decaocto in Europe: colonization patterns in the west of the Iberian Peninsula," Bird Study, vol. 49, no. 1, pp. 11-16, 2002.

[29] J. C. Dunn and A. J. Morris, "Which features of UK farmland are important in retaining territories of the rapidly declining Turtle Dove Streptopelia turtur?" Bird Study, vol. 59, no. 4, pp. 394-402, 2012.

[30] A. F. N. Abd Rabou and M. A. Abd Rabou, "Notes on the pigeons and doves (family columbidae) occurring in the gaza strip-Palestine," Jordan Journal of Natural History, vol. 6, no. $1,2020$.

[31] S. Hanane, "Nest-niche differentiation in two sympatric Streptopelia species from a North African agricultural area: the role of human presence," Ecological Research, vol. 30, no. 4, pp. 573-580, 2015.

[32] I. Mansouri, W. Squalli, H. Achiban, M. Mounir, L. El Ghadraoui, and M. Dakki, "Segregation of breeding habitats and feeding resources among five north African game species in Midelt province, Morocco," Biologia, vol. 77, pp. 137-148, 2021.

[33] R. K. Murton, N. J. Westwood, and A. J. Isaacson, "The feeding habits of the woodpigeon Columba palumbus, stock dove C. Oenas and turtle dove Streptopelia turtur," Ibis, vol. 106, no. 2, pp. 174-188, 1964.

[34] C. Eraud, A. Jacquet, and P. Legagneux, "Post-fledging movements, home range, and survival of juvenile Eurasian collared-doves in Western France," The Condor: Ornithological Applications, vol. 113, no. 1, pp. 150-158, 2011.

[35] N. Saâd, S. Hanane, K. Farhi, and M. D. E. H. Khemis, "Nest age as predictor of nest survival in three sympatric dove species breeding in a mediterranean arid agroecosystem," Ardea, vol. 108, no. 2, pp. 1-12, 2020.

[36] W. Squalli, I. Mansouri, A. El Hassani et al., "Macro-habitat, micro-habitat Segregation and breeding success of the "vulnerable" native European turtle dove and the "invasive" Eurasian collared dove from a North African agricultural area," Biologia, vol. 76, pp. 3743-3750, 2021.

[37] K. Hejlícek and F. Treml, "Epizootiology and pathogenesis of avian mycobacteriosis in doves (Streptopelia sp.)," Veterinarni Medicina, vol. 38, no. 10, pp. 619-628, 1993.

[38] M. C. Martínez-Herrero, M. M. Garijo-Toledo, D. Liebhart et al., "Novel avian oropharyngeal trichomonads isolated from European turtle doves (Streptopelia turtur) and racing pigeons (Columba livia): genetic and morphometric characterisation of clonal cultures," Infection, Genetics and Evolution, vol. 55, pp. 93-103, 2017.

[39] S. Hanane and M. Yassin, "Nest-niche differentiation in two sympatric columbid species from a Mediterranean Tetraclinis woodland: considerations for forest management," Acta Oecologica, vol. 78, pp. 47-52, 2017.

[40] G. Rocha and S. Hidalgo, "La tórtola común Streptopelia turtur," Análisis de los factores que afectan a su status, Universidad de Extremadura, Servicio de Publicaciones, Cáceres, Spain, 2002.

[41] K. A. Ruiz, "Nesting niche partitioning by white-winged and mourning doves with observations of other sympatric
Columbids," Electronic Theses and Dissertations, Texas State University, San Macros, TX, USA, 2012.

[42] A. Gutiérrez-Galán and C. Alonso, "European turtle dove Streptopelia turtur diet composition in Southern spain: the role of wild seeds in mediterranean forest areas," Bird Study, vol. 63, no. 4, 2016.

[43] R. E. Kenward and R. M. Sibly, "A woodpigeon (Columba palumbus) feeding preference explained by a digestive bottle-neck," Journal of Applied Ecology, vol. 14, pp. 815-826, 1977.

[44] S. J. Browne and N. J. Aebischer, "Habitat use, foraging ecology and diet of turtle doves Streptopelia turtur in Britain," Ibis, vol. 145, no. 4, pp. 572-582, 2003.

[45] J. H. Van Niekerk and C. M. Van Ginkel, "The feeding behaviour of pigeons and doves on sown grain crops on the South African Highveld," Ostrich-Journal of African Ornithology, vol. 75, no. 1-2, pp. 39-43, 2004.

[46] A. Kaouachi, M. Menaa, A. C. Rebbah, and M. C. Maazi, "Diet of wood pigeon (Columba palumbus) in forest areas of souk ahras region (NorthEastern Algeria): management implications," Pakistan Journal of Zoology, vol. 53, no. 5, 2020.

[47] S. Nasrine, S. Hanane, F. Kamilia, and M. D. E. H. Khemis, "Nest age as predictor of nest survival in three sympatric dove species breeding in a mediterranean arid agroecosystem," Ardea-Wageningen, vol. 108, 2020.

[48] A. Gutierrez-Galan, A. L. Sanchez, and C. A. GonzáLez, "Foraging habitat requirements of European turtle dove Streptopelia turtur in a mediterranean forest landscape," Aorn, vol. 53, no. 2, pp. 143-154, 2019.

[49] L. E. Biddle, D. C. Deeming, and A. M. Goodman, "Morphology and biomechanics of the nests of the common Blackbird Turdus merula," Bird Study, vol. 62, no. 1, pp. 87-95, 2015.

[50] S. Hanane, "Biométrie des tourterelles des bois Streptopelia turtur dans le sud du Maroc (région de Taroudant),"Ecologia Mediterranea, vol. 36, no. 1, pp. 107-110, 2010.

[51] I. Mansouri, D. Ousaaid, W. Squalli et al., "Nest building, dimension, and selection of aromatic and medicinal twigs to repel ectoparasites in the European Turtle dove," Journal of Animal Behavior, vol. 2021, p. 2133, 2021.

[52] L. E. Biddle, A. M. Goodman, and D. C. Deeming, "Patterns of Construction of Nests Provide Insight into Nest-Building Behaviour," PeerJ, vol. 5, Article ID e3010, 2016. 